\title{
Experimental Study on Flexural Behavior of CBF Bar Reinforced Concrete Beams
}

\author{
Shu Tang ${ }^{a}$, Juan Han ${ }^{b}$ \\ Mianyang Vocational and Technical College, Mianyang, 621000, China \\ atangshu20150915@163.com, bhanjuan1516@163.com
}

\begin{abstract}
Keywords: CBF bar, concrete simple-supported beam, flexural behavior, crack, ultimate bearing capacity

Abstract. Through test on flexural behavior of 2 CBF bar reinforced concrete simple-supported beams on three-point static loading until failure, the experiment researches and analyzes the differences of the crack distribution, the ultimate bearing capacity, the load-deflection relationship and the impact of crack development with the different CBF bar reinforcement ratio. The test results showed that when the reinforcement ratio is within a certain range, the flexural capacity of CBF bar reinforced concrete simple-supported beams increases with the increase in reinforcement radio, and the crack spacing is decreased with the increase in reinforcement radio.
\end{abstract}

\section{Introduction}

CBF bar as a new composite material has good thermal stability, corrosion resistance, fire resistance, impact resistance and light weight, high strength, and resin with high bonding strength, extensive source material and low price. CBF bar replace steel used in concrete structure, it has significant effects on improving the bearing capacity of the structure, reducing structural weight, and improving the structure durability ${ }^{[1]}$.

At present, the domestic scholars' experimental study on CBF bar reinforced concrete beams are relatively less ${ }^{[2-4]}$. Test design makes 2 CBF bar reinforced concrete simple-supported beams, which are tested to failure under static load at three dividing point, to study on the bending behavior which provides some reference for the later designs.

\section{Design and production of CBF bar reinforced concrete beams}

Test materials. Test used the nominal diameter of CBF bar is respectively $8 \mathrm{~mm}$ and $16 \mathrm{~mm}$. It shows that CBF bar is a kind of linear elastic materials by material properties test and their associated performance indicators are shown in Table 1 . In the test, the design strength of concrete is C30, its measured intensity is 33.4MPa. Steel used HRB400 steel, its yield strength is up to 360MPa.

Table 1 Performance indicators of CBF bar

\begin{tabular}{cccccc}
\hline Number & $\begin{array}{c}\text { Diameter } \\
(\mathrm{mm})\end{array}$ & $\begin{array}{c}\text { Mominalarea } \\
\left(\mathrm{mm}^{2}\right)\end{array}$ & $\begin{array}{c}\text { Ultimate Tensile } \\
\text { Strength (MPa) }\end{array}$ & $\begin{array}{c}\text { Elastic Modulus } \\
(\mathrm{GPa})\end{array}$ & $\begin{array}{c}\text { Elongation } \\
\text { Percentage (\%) }\end{array}$ \\
\hline $\mathrm{A}$ & 8 & 50.3 & 1157.8 & 51.3 & 1.9 \\
$\mathrm{C}$ & 16 & 201.1 & 895.4 & 49.7 & 1.7 \\
\hline
\end{tabular}

Specimens design. According to the test section design and reinforcement, the test produced 2 CBF bars super-reinforced beams, the section dimension is $180 \mathrm{~mm} \times 250 \mathrm{~mm} \times 2200 \mathrm{~mm}$. The matching bar condition is shown in Table 2 and the configuration of specimens is shown in Figure. 1. 
Table 2 Specimen Reinforcement

\begin{tabular}{ccccccc}
\hline $\begin{array}{c}\text { Specimens } \\
\text { Number }\end{array}$ & $\begin{array}{c}\text { Compression } \\
\text { zone }\end{array}$ & $\begin{array}{c}\text { Tension } \\
\text { zone }\end{array}$ & Stirrup & $\begin{array}{c}\text { Tension } \\
\text { area } \\
(\mathrm{mm})\end{array}$ & $\begin{array}{c}\text { Boundary } \\
\text { reinforcement } \\
\text { ratio (\%) }\end{array}$ & $\begin{array}{c}\text { Reinforcement } \\
\text { ratio (\%) }\end{array}$ \\
\hline L1 & 2\#8(CBF) & 2\#16(CBF) & S7@100 & 402 & 0.33 & 1.03 \\
L2 & 2\#8(CBF) & $4 \# 16(\mathrm{CBF})$ & S7@100 & 804 & 0.33 & 2.07 \\
\hline
\end{tabular}

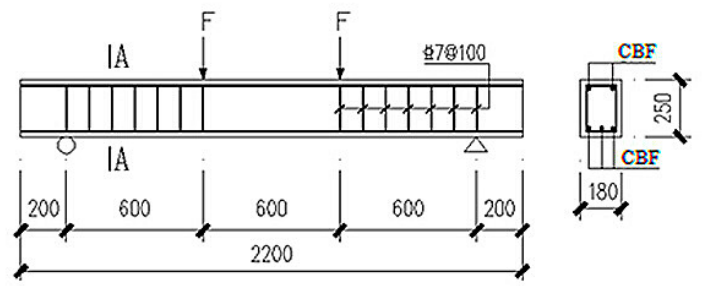

Figure. 1 Configuration of specimens

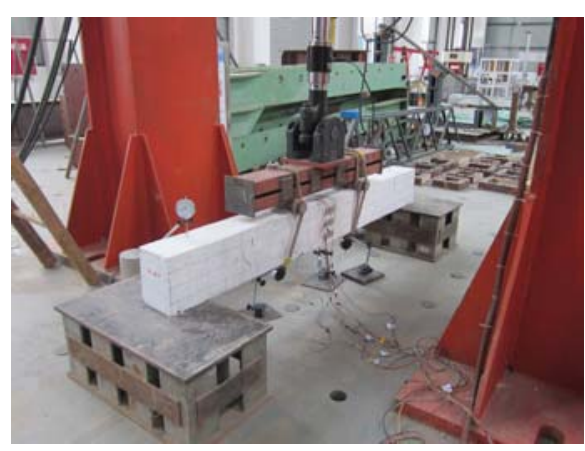

Figure. 2 Load device diagram of specimens

Test measurements and loading scheme. Test uses two-point loading, the loading position and the device is shown in Figure. 2. MTS systems use load control, step loading and each level load is $3 \mathrm{KN}$ before the cracks become. After cracking load is $5 \mathrm{KN}$ for each level, each level is loaded and last 2 minutes, record data and experiment in the recording process. Near failure, load slowly until failure.

\section{Test results analysis}

Test phenomenon analysis. L1 and L2 are similar in the crack development. In the process of loading, the first curved crack appears in the middle of the beam. As the load increases, the crack grows wider and extends across the cross section. Along with the increase of load, the two sides cut the cross section oblique cracks appeared in succession, continue to load, shear stress increases, resulting in a diagonal crack, and both sides of the diagonal cracks are to the beam roof and load center point. As the load continues to increase, the cracks gradually become wide, until the complete destruction, crack characteristics are shown in Figure. 3.

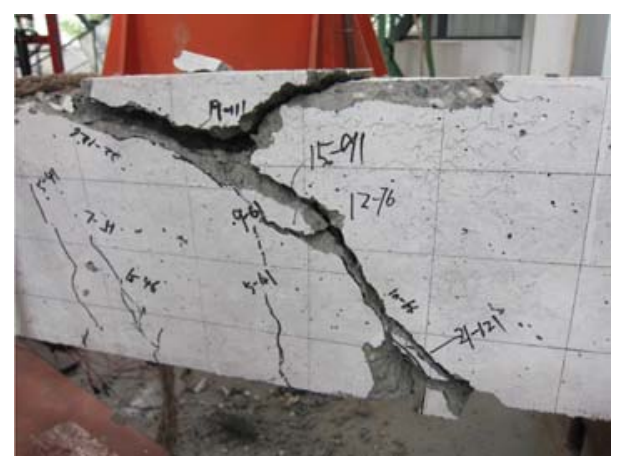

(a) L1

Figure. 3 Crack characteristics

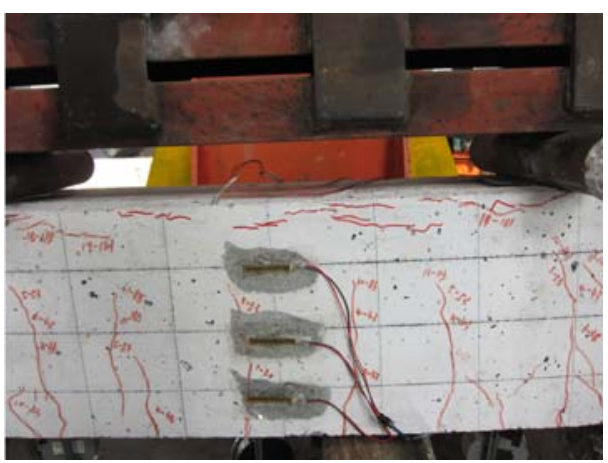

(b) L2

Validation of plane section assumption. From Figure. 4, we can see that the mid span section strain distribution along section height passes through the same point, but doesn't pass through the centroid of the section, the neutral axis of the beams are on the side. The mid-span cross-section strain along the beams section height is basically a line under the each load. The mid-span cross-section concrete strain of beams along the section height passing through the same point position gradually decreased 
with reinforcement ratio increasing. By the above analysis, the strain of the cross section of CBF reinforced concrete beam is basically consistent with the assumption of plane cross section.

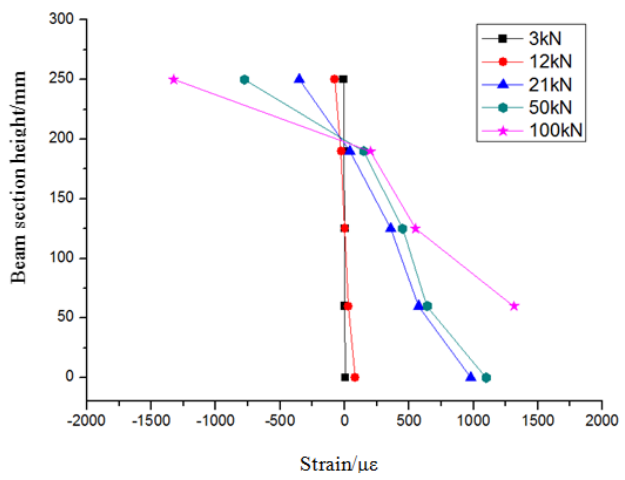

(a) L1

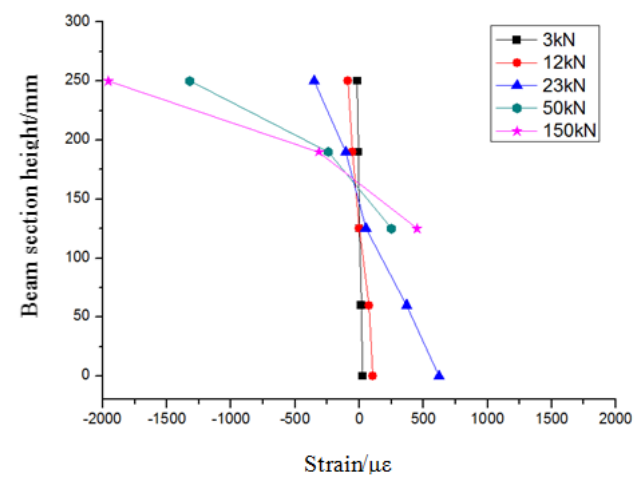

(b) L2

Figure. 4 Distribution of the concrete strain of the beams along the section height

Load deflection analysis. Figure. 5 is shown that from loading to crack appearing, CFB reinforced concrete beam stress grows slowly, and deflection increases rapidly, but the increased rate is very small, the load deflection curve is linear. With the load increases, the tensile strain of concrete at the edge of the tensile zone reaches the ultimate tensile strain, tensile strength reaches the concrete tensile strength of beams, in the weakest section of concrete beam, the first batch of cracks appear, in the cross section of the crack, the concrete is out of the work, and the pulling force of the concrete transferred to the CBF bars, at this time, there was a significant stress redistribution, the tensile stress of CBF bars increases with the load increases. Because of the small elastic modulus of CBF bars, it is very difficult to have a large growth in the stress in the case of small deformation. The flexural capacity of CBF reinforced concrete beams with ordinary concrete beam reinforcement ratio is similar, the higher reinforcement ratio is, the greater the ultimate bearing capacity becomes.

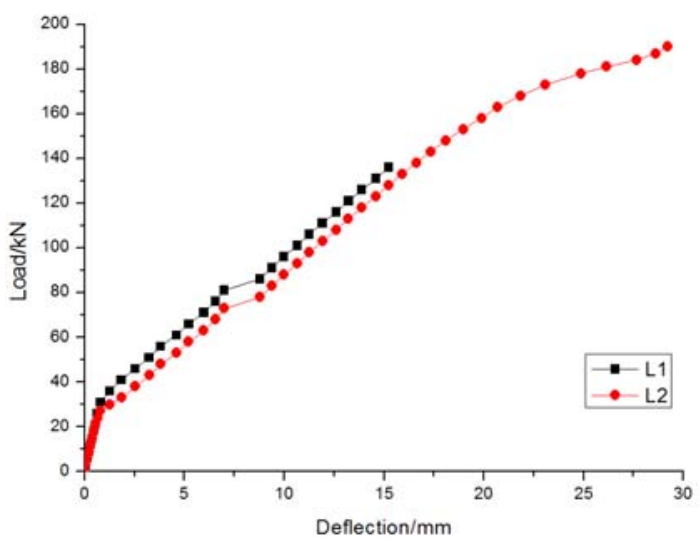

Figure. 5 Load deflection curve

Crack. The maximum crack width is the maximum crack width in the pure bending section of a member under the load of a certain class. A large number of minor cracks appeared before the beam is completely destroyed, and the crack was distributed along the length of the beam. From Figure. 6 it can be seen that the final crack of the three test pieces is mainly distributed along the beam length. The crack width is within $2.5 \mathrm{~mm}$. The crack spacing decreases with the increase of reinforcement ratio, the main reason of the L1 curve sharp drop of is that a crack appears when the beam cracking, while the L2 appears many cracks, the crack spacing is affected by the number of cracks. 


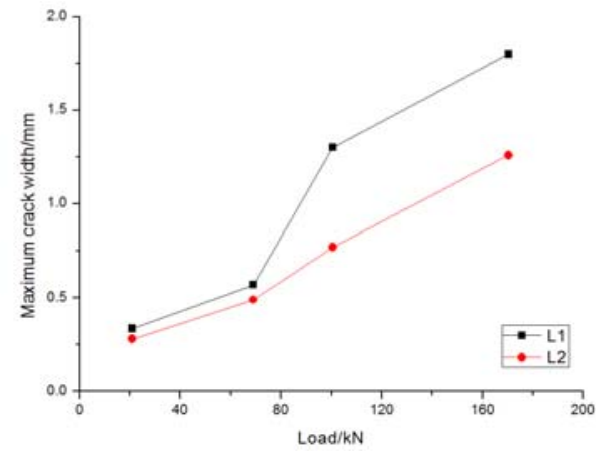

(a) Load-maximum crack width

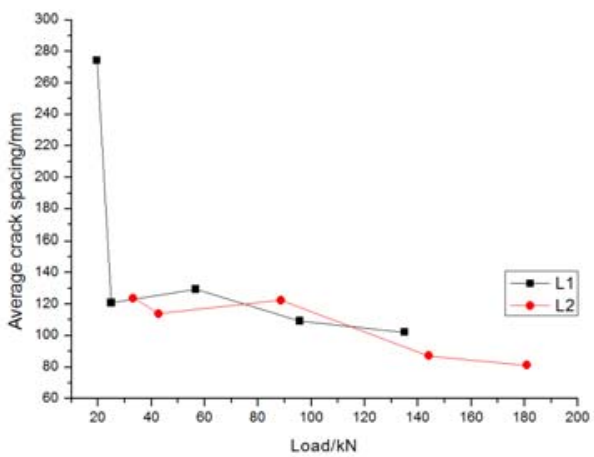

(b) Load-average crack spacing

Figure. 6 The relationship curve of load and crack

\section{Conclusions}

Through the experimental study on CBF bar reinforced concrete simple-supported beams, the conclusions are as follows:

(1) CBF reinforced concrete beams are distributed along the whole beam under the load. The main vertical cracks are caused by the load. The crack width will be crushed and the crack width is within $2.5 \mathrm{~mm}$.

(2) The distribution of strain along the height of the cross section of the beam shows that the cross section of CBF reinforced concrete beams is basically consistent with the assumption that the cross section of CBF reinforced concrete beam is gradually reduced along with the reinforcement ratio increased.

(3) The flexural capacity of CBF reinforced concrete beams with ordinary concrete beam reinforcement ratio is similar, the higher reinforcement ratio is, the greater the ultimate bearing capacity becomes.

\section{References}

[1] Huo Baorong, Zhang Xiangdong. Experimental Study of Mechanical Properties of the BFRP Bar in Different Diameters [J]. Journal of Shenyang Jianzhu University (Natural Science), 2011, 27(4): 626-630.(In Chinese)

[2] Chen Shangjian, Su Xianke. Experimental Study on Behavior of Basalt Fiber Reinforced Polymer (BFRP) [J].Building structure, 2007, 37(supplement): 130-132. (In Chinese)

[3] Wang Wenwei. Study on flexural behavior of reinforced concrete beams strengthened with fiber reinforced plastics (FRP) [D]. Dalian University of Technology, 2003. (In Chinese)

[4] Tian Pan-pan, Pan Mei. Experimental Study on the Flexural Behavior of BFRP Bar Reinforced Concrete Beams [J].Journal of Xinjiang University (Natural Science Edition), 2015, 32(1): 94-99. (In Chinese) 